\title{
Identification of genes involved in flowering in Stevia rebaudiana using expressed sequence tags (ESTs)
}

\author{
Amin Razali, Nurul Hidayah Samsulrizal, Zarina Zainuddin* \\ Department of Plant Science, Kuliyyah of Science, International Islamic University Malaysia, Jalan Sultan Abmad Shah, Bandar Indera \\ Mabkota, 25200 Kuantan, Pahang Malaysia
}

Received 6th April 2020 / Accepted 20th May 2020

\begin{abstract}
Stevia rebaudiana, or stevia, is a perennial herb native to the northern region of South America. It is commercially important due to the high level of non-caloric sweetening compound, which has been consumed worldwide as food and medicine. Stevioside is considered as the most important compound of steviol glycosides that functions as the main sweetener. Exposure of the stevia plant to long-day conditions (increased exposure to light) will delay the flowering process, which led to an increase in glycoside accumulation. The bioinformatics analysis of 5548 expressed sequence tags (ESTs) obtained from dbEST (NCBI) using the Blast2GO software and manual curation identified 7 ESTs that contain domains involved in the flowering process. The domains were the heat shock protein (Hsp) domain, squamosa promoter-binding protein (SBP) domain, CONSTANS, CO-like, and TOC1 (CCT) domains; K homology $(\mathrm{KH})$ domain; and ubiquitin-conjugating enzyme domain (UBC).
\end{abstract}

Keywords: Blast2GO, ESTs, flowering, Stevia rebaudiana

\section{INTRODUCTION}

Stevia rebaudiana is a perennial herb, which belongs to the family of Asteraceae and can live for more than two years and grow up to $1 \mathrm{~m}$ in height (Mishra et al., 2010). This plant is native to the northern regions of South America, where it grows wild near the source of the river Monday and in the Highlands of Amamabay (LemusMondaca et al., 2012). Other countries, such as Korea, Thailand, Brazil, China, and India, also cultivate stevia (Hossain et al., 2017). S. rebaudiana is commercially essential due to the high level of non-caloric sweetening compound that is consumed as food and medicine worldwide. Traditionally, this plant has been used as a sweetener in yerba mate and medicinal teas for the treatment of heartburn and other ailments by the Guarani tribes of Paraguay and Brazil (Brandle \&
Telmer, 2007). As a sweetener, stevia was first commercialised in the food and drug industries by Japan, and now China is the most top producer of stevia extracts with approximately $80 \%$ of total world supply (Research Report on China's Stevia Extract Industry, 2011). Since the sweetening compound in stevia contains zero calorie and is 300 times sweeter than sugar cane, scientists consider this plant to be an effective source of sweetener. Leaves of stevia possess many potential medicinal properties that can be used to treat various chronic and non-chronic diseases, for example, diabetes, obesity, inflammatory bowel disease, cardiovascular disease, and dental caries (Gupta et al., 2013). In addition, the two main compounds, stevioside and rebaudioside A, showed no toxicity effects on human health and

*Author for correspondence: Zarina Zainuddin, Department of Plant Science, Kuliyyah of Science, International Islamic University Malaysia, Jalan Sultan Ahmad Shah, Bandar Indera Mahkota, 25200 Kuantan, Pahang, Malaysia. Email-zzarina@iium.edu.my 
are considered safe for human consumption (Lemus-Mondaca et al., 2012).

Stevia is a photoperiod sensitive plant as photo treated plants have high performance in all the trait studies compared to the control plants (plants grown in Malaysia natural environment). The ability to delay the initiation of flowering and high vegetative yield was obtained by treating the plant with light extension. It has been established that exposing the stevia plant to long days (increased exposure time to light) will delay the flowering process, which leads to increased time for glycoside accumulation (Pal et al., 2015). Ceunen and Geuns (2013) reported similar findings where they found that treating stevia with long-day conditions, prolonged its vegetative growth, and an increment in leaf biomass and total glycosides content was noticed. According to Brandle et al. (1998), stevia needs only 13 hours of day length to trigger the flowering process, so it is classified as a short-day plant. Extensive variability for day-length sensitivity was also reported within the population, where researchers found that light at one foot-candle or even lower can be perceived by some short-day plant. It has been established that flowering of the short-day plants can be delayed by exposing it to long-day condition (Runkle, 2007). The flowering of plants can be initiated after they produced a minimum of four true leaves. According to Parker (2000), the main response of plants to the duration of daylight is flowering. Uninterrupted night or dark period will initiate flower buds. Therefore, to delay flowering (where plants remained vegetative), the dark period needs to be interrupted with a short period of light. According to Yadav et al. (2011), the interval appearance of successive leaf pairs in $S$. rebaudiana was reduced after exposure to long-day conditions where the leaf area, dry weight, and internodes length were increased.

Expressed sequence tags (ESTs) are short single-pass sequence reads acquired from randomly selected cDNA clones (Huang et al., 2017), generally existing within the range of 100700 bp (Gruber, 2007). ESTs were introduced as cost-effective methods for the rapid discovery and characterisation of expressed genes. The establishment of ESTs allows transcript mapping, gene identification, and transcriptional activity description of a tissue or cell type to be studied
(Gruber, 2007). Various genes related to flowering have been identified using ESTs analyses, such as in Eschscholzia californica (Carlson et al., 2006), Gossypium birsutum (Lai et al., 2011), Poncirus trifoliata (Zhang et al., 2008), and Chimonanthus praecox (Sui et al., 2017). Brandle and co-workers (2002) have sequenced and annotated 5548 ESTs from leaf cDNA of stevia and identified the key ESTs involved in diterpene biosynthesis. Other researchers also focused and gave more attention to the identification and expression analysis of steviol glycoside biosynthesis genes using advanced transcriptomic and metabolomic techniques (Chen et al., 2014; Nasrullah et al., 2018). Nonetheless, to date, there is still a lack of research and information on the identification of genes involved in the flowering of $S$. rebaudiana. Hence, the discovery of genes involved in flowering using ESTs would have a great advantage in the ability to manipulate flowering time in the stevia plant. Using biotechnological approaches, the expression of identified flowering genes can be suppressed to produce stevia varieties that are less sensitive to variations in photoperiod and possess delayed flowering characteristic, which are among the essential traits in stevia breeding programme.

\section{MATERIALS AND METHODS}

\section{Selecting ESTs sequence of $S$. rebaudiana} The 5548 stevia ESTs submitted by Brandle et al. (2002) were obtained from the NCBI web page (http://www.ncbi.nlm.nih.gov/dbEST) under the Accession No. BG522659. The fasta ESTs sequence was downloaded where the file name extension was changed from *.txt into *.fasta.

\section{Similarity search using CloudBlast Blast2GO}

All ESTs data were then analysed using the Blast2GO software (B2G software) that was downloaded from https://www.blast2go.com/ blast2go-pro/download-b2gsoftware and installed into the Windows platform using JAVA applications. The Stevia ESTs sequences were loaded into the program. The blast was initiated by selecting Run Blast and choosing CloudBlast from the blast options. Further configuration for CloudBlast used, the blastp-fast (protein 
sequence), was chosen for the blast program, with non-redundant ( $\mathrm{nr}$ ) protein sequence as the blast query sequence. Another parameter added was to reduce the blast hits to 10 (default 20) while maintaining the default blast expectation value $(\mathrm{E}$ value) at $1.0 \mathrm{E}^{-5}$. The project file was saved in the XML/XML2 format with custom file name and directory.

\section{Gene ontology analysis using Blast2GO}

The analysis of ESTs sequences using Blast2GO started with similarity search, mapping, and annotation, where each annotation case was examined at certain reliability levels. The blasted ESTs sequence in XML 'diamond_blast.xml' were loaded into the OmicsBox in a table view. Gene ontology (GO) mapping under functional analysis was then started. Genes with successful mapping in the OmicsBox table were light-green and tagged with 'MAPPED'. GO annotation was then initiated with the default set of annotation configuration. Successful annotation for each query sequence would result in a colour change for that sequence from light-green to blue at the Main Sequence Table, and only the annotated GO will remain in the GO IDs column. The results are visualised and summarised using the GO graph and charts.

\section{Manual selection of candidate genes}

Results from the GO classification were used to identify all genes involved in the flowering pathway using the keyword "flower". The chosen ESTs sequences were further analysed manually using the database in Pfam, InterPro, and NCBI blast website. All information generated from the curation was compared to the sequence table of B2G. The EST sequences were eliminated if they do not meet the criteria.

\section{RESULTS AND DISCUSSION}

\section{Data distribution}

The 5548 stevia ESTs data retrieved from NCBI were analysed by the Blast2GO software. Figure 1 shows the data distribution after analysis. A total of 3257 ESTs (58.7\%) have been annotated, and 266 ESTs (4.8\%) with GO mapping were obtained based on the homology search by
BLAST. The GO terms associated with the hits were retrieved as $\mathrm{GO}$ candidate terms by GO mapping. This particular step creates a pool of GO terms candidate of the gene. From the pool, the GO terms were assigned to the query sequence, a process called GO annotation. This process is done by applying annotation rule (AR) on the found ontology terms. The rule sought to find the most specific annotations with a certain level of reliability (Gene Ontology Consortium, 2019). This shows that more than $50 \%$ gene products were found to be assigned with GO IDs, which described gene-specific function, while genes lower than 5\% were assigned to GO IDs mapped with Enzyme Commission (EC). Meanwhile, 461 ESTs (8.3\%) were blasted without a hit while 5087 ESTs (91.7\%) were blasted with hits. This shows that only 8.3\% ESTs do not have a homology sequence on the database blasted, which consists of short sequences with the length less than $130 \mathrm{bp}$.

\section{Top-hits species distribution}

The analysis also found that Helianthus annuns was the top-hits species distribution for stevia EST sequences with more than 2000 hits, as shown in Figure 2. According to Reagon and Snow (2005), $S$. rebaudiana and $H$. annuus belong to the same family, i.e., Asteraceae. This result shows that most of the genes in both species are more closely related compared to the others.

\section{Gene ontology (GO) distribution}

From Figure 3, 3532 sequences are assigned under the GO classifications of molecular function, biological process, and cellular component. In a biological process, the highest category is the metabolic process, followed by the cellular process. A biological process refers to the gene activity or function involved in a vital process of an organism. A total of 20 categories were noted in the second level of the biological process, with the metabolic and cellular processes being the most dominant at $66 \%$ and $61 \%$. Meanwhile, a high GO distribution was recorded in the molecular function, which comprised of catalytic and binding activities. The molecular function represents the elemental activities of a gene product at the molecular level. About 16 elements have been successfully assigned in the second level of molecular function terms, with catalytic 
activity was found as the dominant elements at $60 \%$. Meanwhile, the cell and cell parts were the higher groups assigned in the cellular components, with $60 \%$ and 59\%. Cellular components describe the parts of a cell or its extracellular environment where the gene was expressed.
Enzyme Commission (EC) Distribution. EC annotation was also performed via Blast2GO. Figure 4 shows that the highest EC class is hydrolase, with more than 375 sequence hits, followed by lyases with more 350 sequence hits. Meanwhile, the lowest EC class is ligase, with only 50 sequence hits. All analyses were specific for the stevia ESTs dataset.

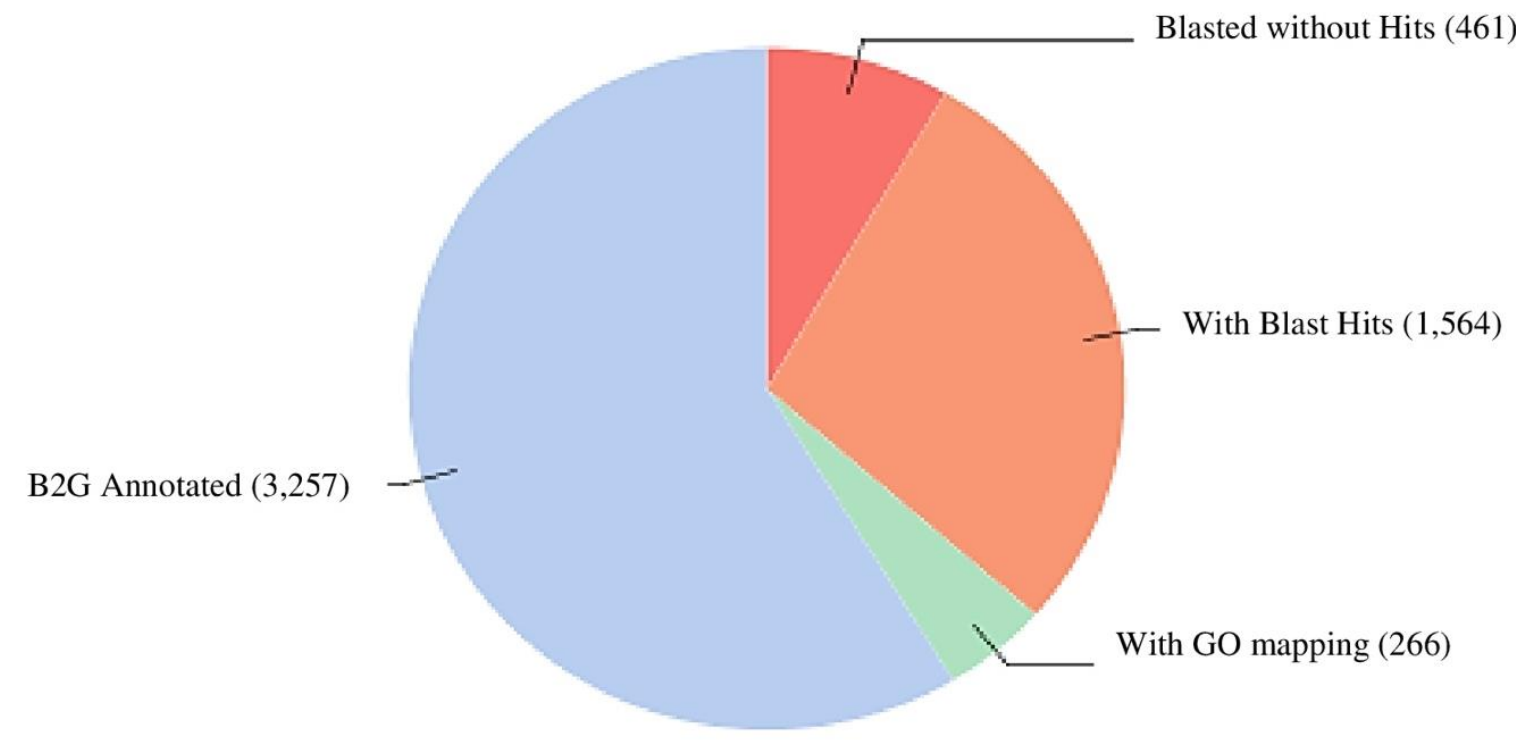

Figure 1. Data distribution after Blast2GO analysis.

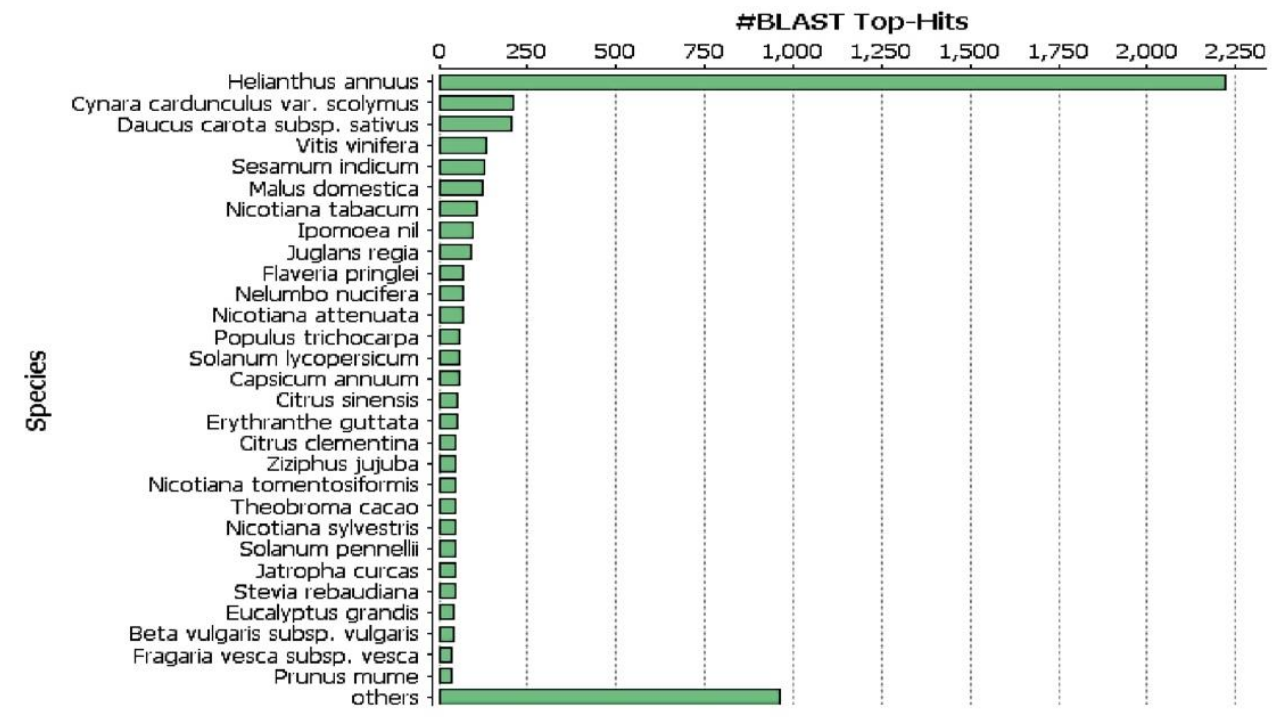

Figure 2. Top-hits species distribution, it displays that $H$. annuus has more than 2000 hits with S. rebaudiana EST followed by Cynara cardunculus var. scolymus and others species. 


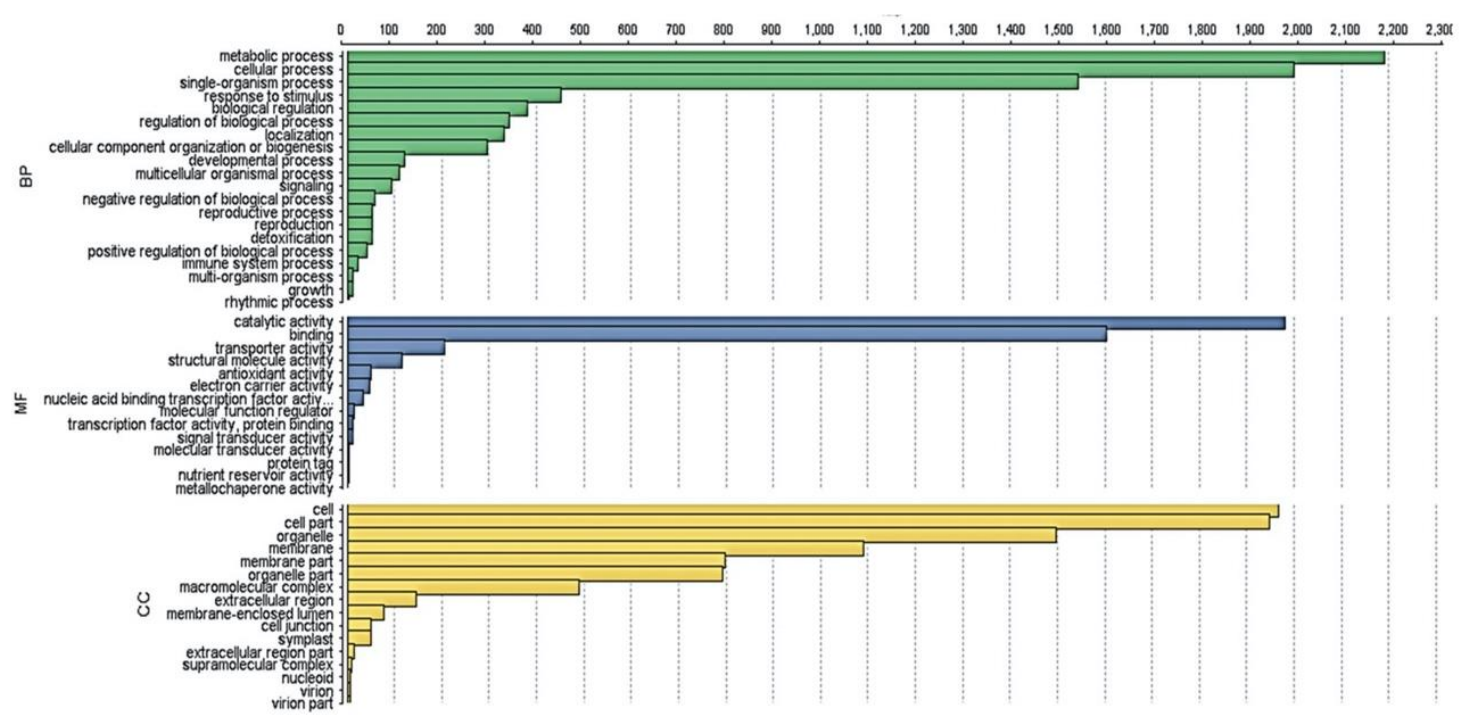

Figure 3. Gene Ontology (GO) distribution: Biology process (BP), Molecular Function (MF), Cellular component (CC).

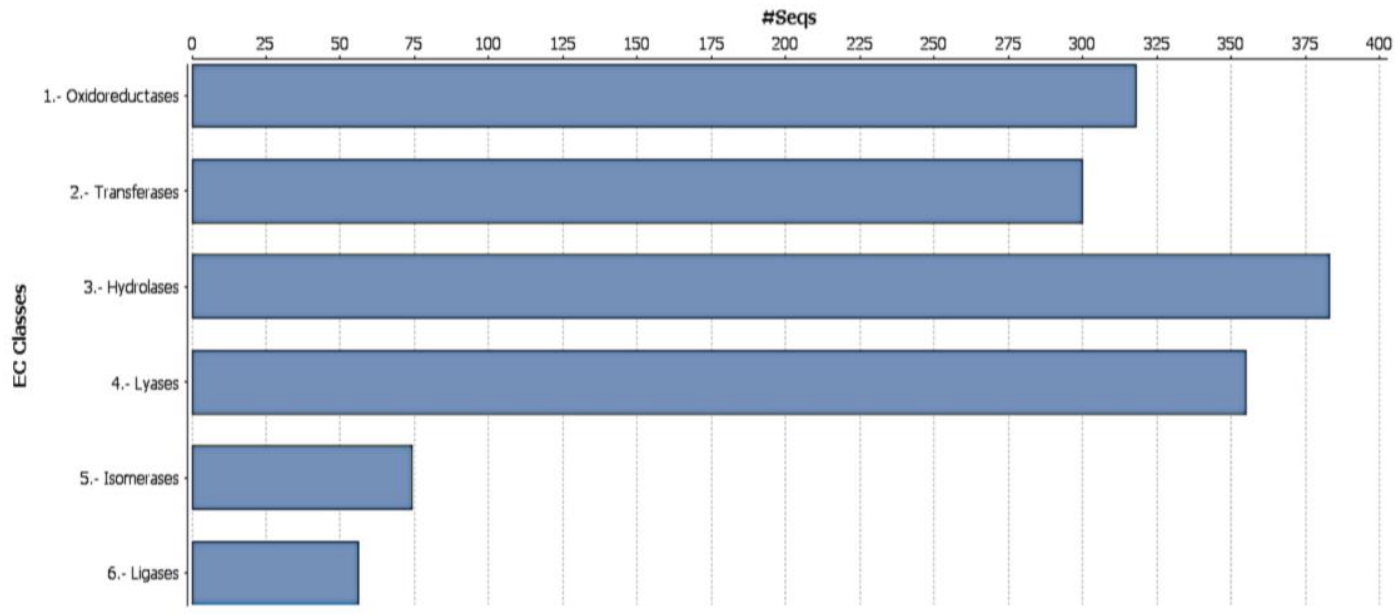

Figure 4. Enzyme Commission (EC) distribution shown that hydrolase has the highest hits with Stevia EST while the lowest hits is ligase.

\begin{abstract}
Analysis of possible genes involved in stevia flowering. Approximately 19 EST sequences that had significant results were chosen for further analysis by manual curation. These sequences were generally chosen based on the keyword "flower" on their B2G results. Based on results from the manual curation and B2G, 12 EST sequences, i.e., BG525836.1, BG525809.1, BG521989.1， BG526310.1， BG523214.1, BG522340.1， BG526257.1， BG522078.1, BG522452.1，BG521670.1，BG525940.1, and BG526019.1 were eliminated as the possible genes that involved in stevia flowering. These ESTs were eliminated either because the InterPro entry does not contain a GO ID as obtained from B2G results or the domains' functions were
\end{abstract}

irrelevant to the flowering process. Meanwhile, the EST sequences of BG525978.1, BG522568.1, BG522277.1， BG524211.1， BG521627.1, BG521658.1, and BG526398.1 were chosen as the possible candidates for genes involved in the flowering process (Table 1). Although the GO ID listed by $B 2 G$ cannot be found during the curation, the E-value from the BLAST search for these sequences is $\mathrm{e}^{-5}\left(10^{-5}\right)$ or lower, which indicate the typical threshold of a good sequence. Besides, these domains were reportedly involved during flowering. Table 1 indicates that the EST sequences of BG525978.1, BG522568.1, and BG522277.1 contain a heat shock 90-2-like and heat shock cognate 80-like domain. Heat shock proteins are the class of proteins induced when 
plants are exposed to various biotic and abiotic stresses (ul Haq et al., 2019). In plant development, it was reported that the HSP90reduced lines of Arabidopsis thaliana were steadily delayed in flowering compared to the controls. It was suggested that the function of the chaperone is either to sense or to integrate environmental signals into the appropriate response (Sangster et al., 2007). Using RNA interference (RNAi) approach, Margaritopoulou et al. (2016) showed that the reduced level of HSP90 mRNA in Arabidopsis abolished flowering. The InterPro entry for this domain is IPR001404.

Squamosa promoter-binding 3 is listed as the domain for EST sequence BG524211.1 (Table 1). Chen et al. (2010) indicated that plant-specific transcription factors that play significant roles in flower and fruit development and plant phase transition are encoded by squamosa promoterbinding protein-like (SPL) genes. The microRNA (miRNA) miR156 regulates many SPL genes in Arabidopsis post-transcription. Kim et al. (2012) found that flowering locus T (FT) expressed in the leaf of Arabidopsis is regulated by the miR156SPL3 module. It also reported that the period of flowering was increased at lower ambient temperature $\left(16^{\circ} \mathrm{C}\right)$ when miR156 was overexpressed. According to Li et al. (2018), SPL genes, which are the targets for miR156, may play a role in flowering through gibberellic acid regulation in Betula luminifera, and the InterPro entry for this domain is IPR004333.

Table 1. ESTs that contain keyword 'flower' based on B2G results.

\begin{tabular}{|c|c|c|}
\hline EST name & Domain & Keyword "flower" \\
\hline BG525978.1 & \multirow{2}{*}{ Heat shock 90-2-like } & \multirow{4}{*}{$\begin{array}{c}\text { P:flower development (GO Names) } \\
\text { P:GO:0009908 (GO ID) }\end{array}$} \\
\hline BG522568.1 & & \\
\hline BG522277.1 & Heat shock cognate 80 -like & \\
\hline BG524211.1 & Squamosa promoter-binding 3 & \\
\hline BG521627.1 & Zinc finger CONSTANS-LIKE 2 & $\begin{array}{l}\text { P:regulation of flower development (GO } \\
\text { Names), P:GO:0009909 (GO ID) }\end{array}$ \\
\hline BG521658.1 & Flowering locus K homology domain-like & \multirow{2}{*}{$\begin{array}{l}\text { Flowering keyword come from Domain name. } \\
\text { P:negative regulation of flower development } \\
\text { (GO Names), P:GO:0009910 (GO ID) }\end{array}$} \\
\hline BG526398.1 & Ubiquitin-conjugating enzyme E2 2 & \\
\hline
\end{tabular}

The EST sequence BG521627.1 shows a zincfinger CONSTANS-LIKE 2 domain. The manual curation revealed that this EST has CONSTANS, CO-like, and TOC1 (CCT) domains. The CCT domain is found near the $\mathrm{C}$ terminus of plant proteins and is a highly conserved basic module of $\sim 43$ amino acids. This domain is often involved in light signal transduction (Strayer et al., 2000). The zinc-finger CONSTANS-LIKE 2 domain is a class in the CCT domain. Under different photoperiodic conditions, CONSTANS (CO) and CONSTAN-like (COL) proteins are key regulators for flowering. In Oryza sativa, for example, overexpression of COL9 leads to the delay in flowering time, through the repression of the EhD1 pathway (Liu et al., 2016). The InterPro entry for this domain is IPR010402.

From the B2G analysis, EST sequence BG521658.1 was identified to have flowering locus $\mathrm{K}$ homology domain-like. The K homology $(\mathrm{KH})$ domain, which was first identified in human heterogeneous nuclear ribonucleoprotein (hnRNP) K, can be found in diverse nucleic acid recognition motifs in proteins (Valverde et al., 2008). It is a domain of around 70 amino acids and was discovered in various proteins in archaea, bacteria, and eukaryotes (Grishin, 2001). Mockler et al. (2004) studied the regulation of flowering time in $A$. thaliana by $\mathrm{K}$ homology domain proteins. Putative RNA-binding protein with three $\mathrm{KH}$ domains was encoded by the floweringtime gene, flowering locus $\mathrm{KH}(F L K)$ domain. The FLK mutation, with the domain entry of IPR004088, caused a delay in flowering in $A$. thaliana.

The EST sequence BG526398.1 has ubiquitin-conjugating enzyme E2 2 (InterPro ID: IPR000608) as its domain. This ubiquitinconjugating enzyme (UBC or E2 enzyme) functions to catalyse the attachment of ubiquitin to cellular proteins (Stewart et al., 2016). The activation of FLC expression and repression of flowering in $A$. thaliana involved the E2 ubiquitinconjugating enzymes, AtUBC1 and AtUBC2 that play redundant roles in $A$. thaliana. These enzymes are involved in the activation of flowering locus $\mathrm{C}$ 
(FLC) expression and flowering repression in $A$. thaliana (Xu et al., 2009).

\section{CONCLUSION}

The ESTs of $S$. rebaudiana were successfully analysed using bioinformatics tools. From the analyses done on 5548 stevia ESTs obtained from dbEST (NCBI), 7 ESTs may contain genes involved in the flowering process, namely BG525978.1， BG522568.1， BG522277.1, BG524211.1, BG521627.1, BG521658.1, and BG526398.1. These ESTs contain domains that were revealed to be involved in the flowering process. The domains are heat shock proteins (HSPs) domain; squamosa promoter-binding protein (SBP) domain; CONSTANS, CO-like, and TOC1 (CCT) domains; $\mathrm{K}$ homology $(\mathrm{KH})$ domain; and ubiquitin-conjugating enzyme domain (UBC). Further verification of the functions and involvements of the putative ESTs identified in this work in flowering is needed and can be done through RT-PCR and RNA-seq data. The identification of flowering genes will be useful for the breeding programme of stevia with the desired trait of photoperiod insensitivity.

\section{ACKNOWLEDGEMENTS}

We would like to acknowledge International Islamic University Malaysia for the financial support under grant RIGS16-108-0272.

\section{REFERENCES}

Brandle, J. E., Starratt, A. N., \& Gijzen, M. 1998. Stevia rebaudiana. Its biological, chemical and agricultural properties. Canadian Journal of Plant Science 78(4): 527-536.

Brandle, J. E., Richman, A., Swansom, A. K., \& Chapman, B. P. 2002. Leaf ESTs from Stevia rebaudiana: a resource for gene discovery in diterpene synthesis. Plant Molecular Biology 50(45): 613-622.

Brandle, J. \& Telmer, P. 2007. Steviol glycoside biosynthesis. Phytochemistry 68: 1855-1863.

Carlson, J. E., Leebens-Mack, J. H., Wall, P. K., Zahn, L. M., Mueller, L. A., Landherr, L. L., Hu, Y., Ilut, D. C., Arrington, J. M., Choirean, S., Becker, A., Field, D., Tanksley, S. D., Ma, H., \& dePamphilis, C. W. 2006. EST database for early flower development in California poppy
(Eschscholizia californica Cham., Papaveraceae) tags over 6000 genes from a basal eudicot. Plant Molecular Biology 62(3): 351 369.

Ceunen, S. \& Geuns, J. M. 2013. Influence of photoperiodism on the spatio-temporal accumulation of steviol glycosides in Stevia rebaudiana (Bertoni). Plant Science 198: 72-82.

Chen, J., Hou, K., Qin, P., Liu, H., Yi, B., Yang, W., \& Wu, W. 2014. RNA-Seq for gene identification and transcript profiling of three Stevia rebuadiana genotypes. BMC Genomics 15(571): 1-11.

Chen, X., Zhang, Z., Liu, D., Zhang, K., Li, A., \& Mao, L. 2010. SQUAMOSA promoter-binding protein-like transcription factors: star players for plant growth and development. Journal of Integrative Plant Biology 52(11): 946-951.

Gene Ontology Consortium. 2019. The gene ontology resource: 20 years and still GOing strong. Nucleic Acid Research 47(D1), D330-D338.

Grishin, N. V. 2001. KH domain: One motif, two folds. Nucleic Acid Research 29: 638-643.

Gruber, A. 2007. Expressed Sequence tags. In: Bioinformatics: Methods Express. Ed. Dear, P. H. Scion Publishing Limited, USA.

Gupta, E., Purwar, S., Sundaram, S., \& Rai, G. K. 2013. Nutritional and therapeutic values of Stevia rebaudiana: A review. Journal of Medicinal Plants Research 7(46): 3343-3353.

Hossain, M. F., Islam, M. T., Islam, M. A., \& Akhtar, S. 2017. Cultivation and uses of Stevia (Stevia rebaudiana Bertoni): A review. African Journal of Food, Agriculture, Nutrition and Development 17(4): 12745-12757.

Huang, X., Yang, 1., Jin, Y., Lin, J., \& Liu, F. 2017. Generation, annotation, and analysis of a large-scale expressed sequence tag library from Arabidopsis pumila to explore salt-responsive genes. Frontiers in Plant Science 8(955): 1-15.

Kim, J. J., Lee, J. H., Kim, W., Jung, H. S., Huijser, P., \& Ahn, J. H. 2012. The microRNA156-squamosa promoter binding protein-like3 module regulates ambient temperatureresponsive flowering via flowering locus $\mathrm{T}$ in Arabidopsis. Plant Physiology 159(1): 461-478.

Lai, D., Li, H., Fan, S., Song, M., Pang, C., Wei, H., Liu, J, Wu, D., Gong, W., \& Yu, S. 2011. Generation of ESTs for flowering gene discovery and SSR marker development in upland cotton. PLOS ONE 6(12): e28676.

Lemus-Mondaca, R., Vega-Ga $\square$ lvez, A., Zura-Bravo, L., \& AhHen, K. 2012. Stevia rebaudiana Bertoni, source of a highpotency natural sweetener: A comprehensive review on the biochemical, nutritional and functional aspects. Food Chemistry 132: 1121-1132.

Li, X-Y., Lin, E-P., Huang, H-H., Niu, M-Y., Tong, Z-K., \& Zhang, J-H. 2018. Molecular characterization of squamosa promoter binding protein-like (SPL) gene family in Betula luminifera. Frontiers in Plant Science 9(608): 1-17.

Liu, H., Gu, F., Dong, S., Liu, W., Wang, H., Chen, Z., \& Wang, J. 2016. CONSTANS-like 9 (COL9) delays the flowering time in Oryza sativa by repressing the Ehd1 pathway. Biochemical and Biophysical Research Communications 479(2016): 173-178.

Margaritopoulou, T., Kryovrysanaki, N., Megkoula, P., Prassinos, C., Samakovli, D., Miloni, D., \& Hatzopoulos. 2016. HSP90 canonical content organizes a molecular scaffold mechanism to progress flowering. The Plant Journal 87: 174197.

Mishra, P., Singh, R., Kumar, U., \& Prakash, V. 2010. Stevia rebaudiana - A magical sweetener. Global Journal of Biotechnology \& Biochemistry 5: 62-74.

Mockler, T. C, Yu, X., Shalitin, D., Parikh, D., Michael, T. P., Liou, J., Huang, J., Smith, Z., Alonso, J. M., Ecker, J. R., Chory, J., \& Lin C. 2004. Regulation of flowering time in Arabidopsis by $\mathrm{K}$ homology domain proteins. Proceedings of the 
National Academy of Sciences of the United States of America 101(34): 12759-12764.

Nasrullah, N., Ahmad, J., Salfi, M., Rafiqi, U., Quadri, N., Shah, I. G., \& Abdin, M. Z. 2018. Metabolic profiling and expression analysis of key genes during leaf maturation of Stevia rebaudiana Bertoni. Pharmacognosy Magazine 14: S327S334.

Pal, P. K., Kumar, R., Guleria, V., Mahajan, M., Prasad, R., Pathania, V., Gill, B. S., Singh, D., Chand, G., Singh, B., Singh, R. D., \& Ahuja, P. S. 2015. Crop-ecology and nutritional variability influence growth and secondary metabolites of Stevia rebaudiana Bertoni. BMC Plant Biology 15: 1-16.

Parker, R. 2000. Introduction to Plant Science. New York: Delmar Publisher, pp 62-78.

Reagon, M. \& Snow, A. A. 2005. Cultivated Helianthus annuus (Asteraceae) volunteers as a genetic "bridge" to weedy sunflower populations in North America. American Journal of Botany 93(1): 127-133.

Research Report on China's Stevia Extract Industry. 2011. Research and Markets: Research Report on China's Stevia Extract Industry - 2011 - 2012. http://www.reuters.com/ article/2011/01/31/ idUS210042+31-Jan 2011+BW20110 131.

Runkle, E. 2007. Technically speaking: Providing long days. Greenbouse Product News 17 (1): 66.

Sangster, T. A., Bahrami, A., Wilczek, A., Watanabe, E., Schellenberg, K., McLellan, C., Kelley, A., Kong, S. W., Queitsch, C., \& Lindquist, S. 2007. Phenotypic diversity and altered environmental plasticity in Arabidopsis thaliana with reduced Hsp90 levels. PLoS One 2(7): e648.

Stewart, M. D., Ritterhoff, T., Klevit, R. E. \& Brzovic, P. S. 2016. E2 enzymes: more than just middle men. Cell Research 26: 423-440.

Strayer, C., Oyama, T., Schultz, T. F., Raman, R., Somers, D. E., Mas, P., Panda, S., Kreps, J. A., \& Kay, S. A. 2000. Cloning of the Arabidopsis clock gene TOC1, an autoregulatory response regulator homolog. Science 289(5480): 768-771.

Sui, S., Luo, J., Ma, J., Zhu, Q., Lei, X., \& Li, M. 2017. Generation and analysis of expressed sequence tags from Cbimonanthus pracox (Wintersweet) flowers for discovering stressresponsive and floral development-related genes. Comparative and Functional Genomics 2012: 1-13.

ul Haq, S. Khan, A., Ali, M. Khattak, A. M., Gai, W-X., Zhang, HX., Wei, A-M., \& Gong Z-H. 2019. Heat shock proteins: Dynamic biomolecules to counter plant biotic and abiotic stresses. International Journal of Molecular Sciences 20: 1-31.

Valverde, R., Edwards, L., \& Regan, L. 2008. Structure and function of KH domains. The FEBS Journal 275: 2712-2726.

Xu, L., Ménard, R., Berr, A., Fuchs, J., Cognat, V., Meyer, D., \& She, W. 2009. The E2 ubiquitin-conjugating enzymes, AtUBC1 and AtUBC2, play redundant roles and are involved in activation of FLC expression and repression of flowering in Arabidopsis thaliana. The Plant Journal 57(2): 279288.

Yadav, A. K., Singh, S., Dhyani, D., \& Ahuja, P. S. 2011. A review on the improvement of stevia [Stevia rebaudiana (Bertoni)]. Canadian Journal of Plant Science 91(1): 1-27.

Zhang, J-Z., Li, Z-M., Liu, L., Mei, L., Yao, J-L., \& Hu, C-G. 2008. Identification of early-flower-related ESTs in an earlyflowering mutant of trifoliate orange (Poncirus trifoliata) by suppression subtractive hybridization and microarray analysis. Tree Physiology 28: 1449-1457. 